\title{
INNOVACIÓN COMO VENTAJA COMPETITIVA EN LAS EMPRESAS ARTESANALES EN TONALÁ, JALISCO
}

Innovation as a Competitive Advantage in the Craft Enterprises in Tonalá, Jalisco

\author{
Agustín Jorba-Mata ${ }^{1}$ \\ Fernando de Jesús Salcedo Medina ${ }^{2}$ \\ Ensayo recibido: Enero, 2017 // Aceptado:Marzo, 2017
}

\section{RESUMEN}

Las artesanías es el principal atractivo del municipio de Tonalá, Jalisco, destacando la fabricación de alfarería y cerámica en diferentes piezas como platos, platones, jarros, cantaros, cazuelas, ollas maceteros, floreros, piezas en miniatura, figuras decorativas, entre otras. Desgraciadamente hoy en día es más común la venta de una gran gama de productos importados principalmente de China, a bajos precios pero de mala calidad, y la venta de productos piratas es también uno de los aspectos que han causado controversia. Esto ocasiona una competitividad extrema y se vuelve necesario transformar los procesos productivos como también los mismos

\section{AbSTRACT}

The handicraft is the main attraction of the town of Tonala, Jalisco, emphasizing pottery and ceramics in different pieces like plates, platters, jugs, pitchers, bowls, pots, planters, vases, miniatures, decorative figurines, etc. Unfortunately, today, more common is the sales of a wide range of products imported mainly from China at low prices but of poor quality, and the sale of pirate products is also one of the issues that has caused discussions. This causes extreme competitiveness and it creates the necessity to transform production processes as well as the products themselves. The aim of this work is to use

1 Doctor em Administración Pública. Profesor investigador del Departamento de Administración y de Economía. Centro Universitario de Ciencias Económico Administrativas. Universidad de Guadalajara. Líneas de Investigación: Economía organizacional, administración estratégica. Dirección: Av. Periférico Norte $\mathrm{N}^{\circ} 799$, Núcleo Universitario Los Belenes,C.P.45100, Zapopan, Jalisco, México. Tel. +523337703340 Ext. 25685. E-mail: gusajm@yahoo.com

${ }^{2}$ Maestría en Negocios y Estudios Económicos. Profesor investigador del Departamento de administración y de Economía. Centro Universitario de Ciencias Económico Administrativas. Universidad de Guadalajara. Líneas de Investigación: Economía organizacional, administración estratégica. Dirección: Av. Periférico Norte $\mathrm{N}^{\circ} 799$, Núcleo Universitario Los Belenes, C.P.45100, Zapopan, Jalisco, México. Tel. +523337703340 Ext. 25685. E-mail: pan051089@ hotmail.com. 
productos. El objetivo de este trabajo es utilizar la teoría basada en la industria, en los recursos, el pensamiento estratégico, las perspectivas empresariales y la innovación como posibilidades para la adaptación y resiliencia de las empresas artesanales, para que ellas puedan permanecer en el mercado.

Palabras clave: Artesanías; Tonalá; innovación; competitividad. innovation as a competitive strategy for small businesses to stay in the market.

Key words: Handicrafts, Competitiveness, Innovation, Tonala.

\section{INTRODUCCIÓN}

La artesanía en México refleja la diversidad cultural y la riqueza creativa de sus pueblos y antepasados. Tonalá es una palabra de la lengua náhuatl que proviene de Tonállan (de tonálli, que signifíca sol, y lan, que quiere decir lugar). Se trata de una población de origen indígena, históricamente asociada a la tradición artesanal, actividad que hasta nuestros días le confiere una especialización reconocida a nivel nacional e internacional debido a las finas piezas de cerámica que ahí se producen (Cabrales, 2000).

Tonalá es el municipio de Jalisco que se distingue por producir artesanías típicas de la región. Esta actividad está organizada en pequeños talleres familiares que solo trabajan con los sistemas manuales y técnicas tradicionales. Esto permite que los productos elaborados contengan un alto valor histórico, cultural, artístico y turístico. Las actividades artesanales principales son la alfarería, papel maché, figuras de hierro forjado, vidrio soplado, muebles, pinturas, etc.

Las técnicas y los saberes artesanales son reconocidos internacionalmente, ya que todas las piezas producidas representan el arte mexicano en todo el mundo. Este es uno de los medios más importantes para proyectar la cultura, y es una de las principales razones por las cuales numerosas personas visitan el municipio de Tonalá. Es muy importante señalar, asimismo, que Tonalá exporta artesanías por todo el mundo, por ejemplo a Estados Unidos, Canadá, Europa, Australia y América Latina.

En la actualidad, la competencia y subsistencia de las organizaciones artesanales es cada vez más exigente debido a que el mundo se hace más estrecho y pequeño por la globalización del comercio y de las empresas. Las pequeñas empresas locales están obligadas a diseñar 
y proponer nuevos productos que les permitan diferenciarse de las importaciones y las empresas extranjeras y, al final, poder contribuir al apalancamiento de éstas hacia la obtención de ventajas competitivas.

En este artículo proponemos que el sector artesanal podría superar el desafío actual, si explota sus ventajas competitivas. Esas ventajas deben estar fundamentadas o basadas en componentes organizacionales que promuevan la calidad, los procesos eficaces, el acceso a los mercados, y muy especialmente el desarrollo de los productores. Por lo tanto, esos componentes deben estar sujetos a un permanente cambio y actualización, como así también deben ser el resultado de la aplicación de procesos de innovación. En esta situación, las pequeñas empresas artesanales pueden adaptarse y ser resilientes a la competencia del mercado global, siempre y cuando revisen sus mecanismos de gestión y fortalezcan los procesos de innovación en la organización.

Este estudio sintetizará los resultados de investigación en torno a las razones que justifican la innovación como un factor clave para el logro de ventajas competitivas de las pequeñas y medianas empresas que producen artesanías en Tonalá. Por medio de la aproximación del caso de Tonalá, el artículo tiene el propósito de generar un conocimiento que pueda ser de utilidad para el análisis y la comparación con otros casos de sectores artesanales que se ven enfrentados a desafíos similares. La metodología consistió en revisar gran cantidad de literatura sobre ventajas comparativas, gestión y procesos de innovación, que fue complementada con información sobre el sector artesanal en Tonalá, obtenida por medio de la observación de campo y entrevistas aplicadas a algunos artesanos.

La primera parte del artículo está referida al sector artesanal de Tonalá y su relevancia en la economía regional, con información cuantitativa y cualitativa. La segunda parte está destinada a sintetizar los argumentos sobre las ventajas competitivas, la innovación, las teorías basadas en la industria y los recursos, el pensamiento estratégico, las perspectivas empresariales. La tercera parte presenta un modelo de relación para promover la adaptación del sector artesanal. La cuarta y última parte está referida al papel de la innovación y sus potencialidades para el sector de las artesanías, y la visión de los artesanos consultados en Tonalá. Las conclusiones subrayan la importancia del enfoque de ventajas competitivas y la innovación para la adaptación del sector artesanal. 


\section{LA RELEVANCIA DEL SECTOR ARTESANAL}

El municipio de Tonalá representa el $21 \%$ de la superficie total de Jalisco. Colinda al Norte con los municipios de Guadalajara y Zapotlanejo, al Este con el municipio de Zapotlanejo, al Sur con los municipios de Juan Acatlán y El Salto y al Oeste con los municipios de El Salto, Tlaquepaque y Guadalajara. Cuenta con una población total de 337.149 habitantes.

Figura 1. Ubicación de Tonalá

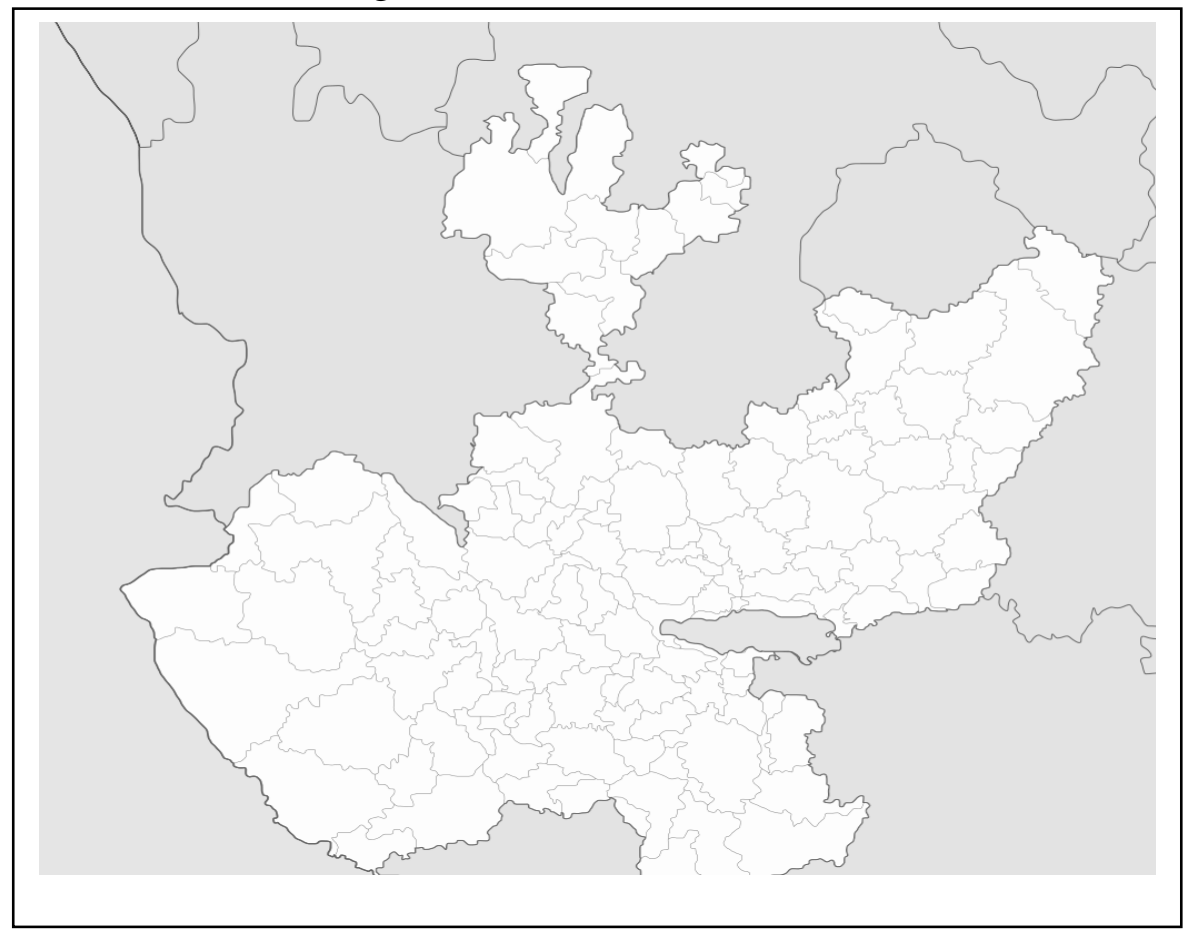

Fuente: Google Earth, 2014 
Figura 2. Municipio de Tonalá

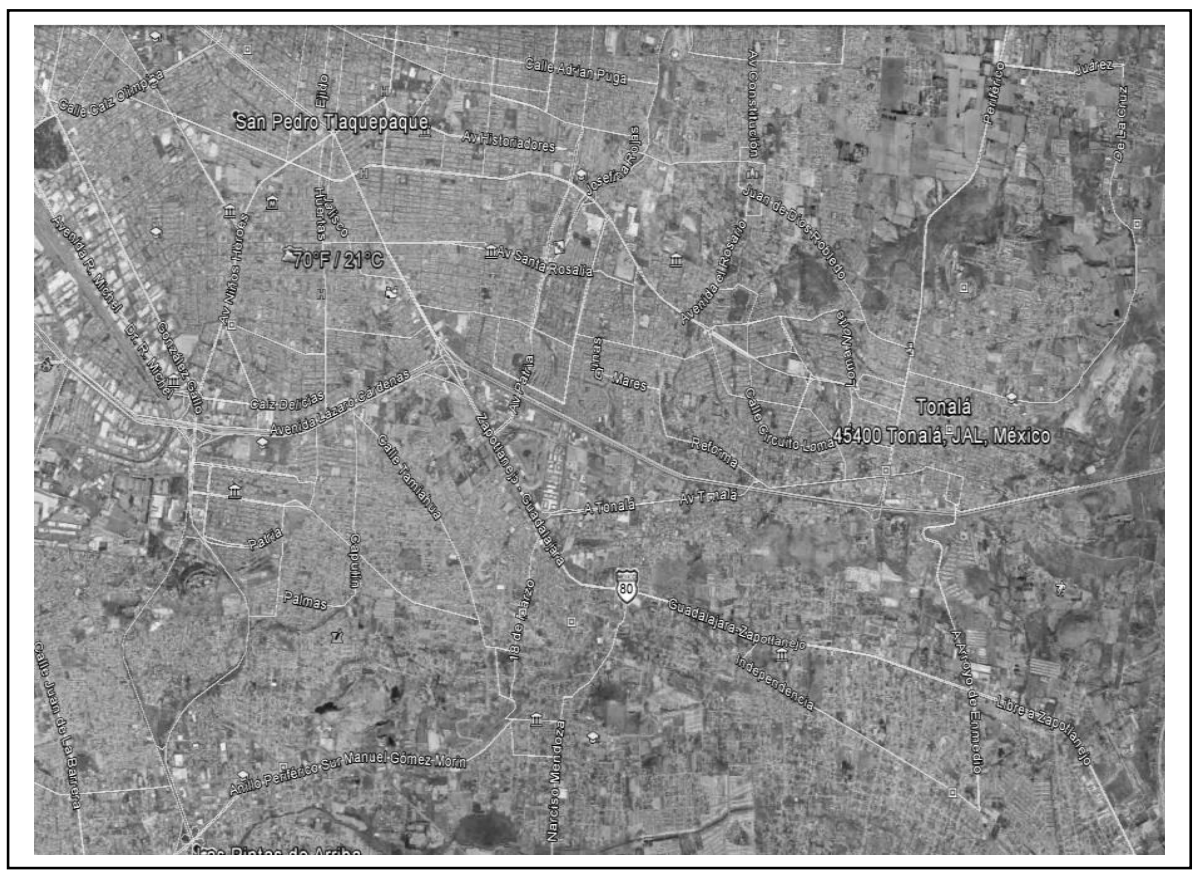

Fuente: Google Earth, 2014

El subsector donde se encuentran la rama de la alfarería y la cerámica representa el $12,59 \%$ del total de unidades económicas en la industria manufacturera de Jalisco, mientras que la rama representa el $38,29 \%$ del total de unidades económicas en el Estado. En lo referente a personal ocupado, constituye el $25,95 \%$. En unidades económicas, la rama ocupa el primer lugar frente a las demás del subsector; mientras que en el aspecto del personal ocupado se encuentra apenas por debajo de la rama de fabricación de cemento, cal y otros productos, que cuentan con el $35,44 \%$ del total del subsector en este rubro (Cuadro 1). 
Cuadro 1. Número de Unidades por tipo de industria y la cantidad de personal ocupado por cada una

Producción de bienes a base de minerales no metálicos en Jalisco

\begin{tabular}{lll}
\hline Industria & $\begin{array}{l}\text { Unidades } \\
\text { económicas }\end{array}$ & Personal Ocupado
\end{tabular}

Alfarería y cerámica.

1.339

5.314

Fabricación de materiales de arcilla

1.259

3.783

para la construcción

Fabricación de productos de vidrio

179

4.123

Fabricación de Cemento, cal, yeso y

720

7.258

otros minerales no metálicos

Total

3.497

20.478

Industria manufacturera de Jalisco

27.784

325.616

Fuente: INEGI (2010)

Tonalá cuenta con el 58,02\% de las unidades económicas del subsector manufacturero, correspondiente a los productos minerales no metálicos en la zona Metropolitana de Guadalajara, proporcionando 
empleo al $41.58 \%$ del total de personal ocupado en el subsector (Cuadro 2).

Cuadro 2. Unidades económicas en los municipios de la zona metropolitana de Guadalajara (ZMG) con el número de personas ocupadas.

Productos minerales no metálicos

\begin{tabular}{lll}
\hline Municipios ZMG & Unidades económicas & Personal ocupado
\end{tabular}

Guadalajara

Zapopan

Tonalá

Tlaquepaque

Total

2.287
2.210

2.496

5.410

2.894

13.010

Fuente: INEGI (2010)

Lo anterior pone en evidencia peso económico del municipio sobre los demás que integran la ZMG, en lo que se refiere a la fabricación de productos minerales no metálicos, por la abundancia de sus unidades económicas en este rubro, entre las que evidentemente las artesanías tienen un papel preponderante.

En Tonalá, la industria manufacturera cuenta con el 9,40\% de las unidades económicas con respecto al total estatal. De los subsectores, el de Productos Minerales no Metálicos tiene el mayor peso específico dentro 
de la industria, al contar con el 50,80\% de las unidades económicas de la industria y con el 49,13\% del personal ocupado a nivel municipal (Cuadro $3)$.

Cuadro 3. Comparación de la Industria manufacturera de Tonalá con otras industrias.

Industria Manufacturera, Tonalá, Jalisco

Alimentos bebidas y tabaco

Textiles, prendas de vestir e industria del cuero

Madera y productos de madera
Industria

Personal

Ocupado

402

1.566

110

815

57

239

editoriales

Sustancias químicas derivadas del petróleo, 54

197 caucho y plástico

Productos minerales no metálicos

Industria metálica básica

13

54

Productos metálicos, maquinaria y equipo

354

1.307 
Otras industria manufactureras

Total
38

209

Se evidencia, de esta manera, la importancia de la producción de este tipo de bienes en la industria de la región.

La fabricación de artesanías representa un recurso económico para millones de artesanos que viven de ella y que por medio de cooperativas y sociedades exportan sus productos a países miembros de la Unión Europea, Canadá, Estados Unidos, por citar algunos ejemplos. Según registros del INI-CONAPO, existe un total de 33.730 .210 millones de indígenas en México. Del total de población indígena, 9.348 .109 (28.7\%) dedican su vida a actividades del sector secundario, por lo que la producción artesanal en México representa una pequeña porción de la economía global. Además, el $43.6 \%$ de esta población de artesanos indígenas recibe diariamente un ingreso de 2 salarios mínimos aproximadamente, (\$3.50 U.S. Dollar), mientras que el resto de la población está por debajo de los 2 salarios mínimos.

\section{LAS ARTESANÍAS Y LA INNOVACIÓN}

La artesanía en México, y hablando en esta caso de las artesanías de Tonalá Jalisco, reflejan la diversidad cultural y la riqueza creativa de nuestros país y nuestros antepasados.

Las empresas de artesanías tienen gran trayectoria en Jalisco, como por ejemplo los alfareros de Tonalá que en el pasado llevaban a vender sus productos artesanales a Guadalajara, cargándolas en burro. En barcinas empacaban sus mercancías y la cargaban en el lomo del animal llevando su mercancía hasta Guadalajara, al mercado de san Juan de Dios, donde vendían sus muy bonitos productos.

Los días de mercado eran los domingos y los lunes, entre las artesanías más apreciadas estaban los jarros, ollas, vajillas, cazuelas y también los botellones para contener agua (Moctezuma, 2002). Algunos 
de estos productos se fabrican muy poco actualmente. Sin embargo, otros estilos se han conservado y desarrollado exitosamente con el tiempo, como las cazuelas bruñidas y las vajillas estilo petatillo.

Relacionar estas empresas artesanales con el concepto de innovación no es, de ningún modo, una idea descabellada. Por el contrario, la innovación es un elemento que se constituye esencialmente para lograr que las empresas sean competitivas, independientemente de que sean grandes o pequeñas. Cuando hablamos de las pequeñas empresas, la necesidad de innovación se vuelve más apremiante dadas las características propias de este tipo de empresas, operando en contextos complejos y de alta incertidumbre. Es por ello que Arias (Arias, 2000), al tratar a las empresas productoras de artesanías, argumenta que éstas no deben quedar exentas de la aplicación del concepto de innovación.

De hecho, los cambios en la actividad artesanal siempre han estado presentes en Tonalá en muy diversos aspectos, por ejemplo: la cerámica que elaboraban los indígenas antes de la conquista experimentó su primer cambio con la llegada de los españoles, quienes introdujeron el vidriado de las piezas de alfarería y el torno. El vidriado fue rápidamente asimilado por los tonaltecas, pues permitía una mayor consistencia y durabilidad a las vasijas utilitarias.

En la década de 1960 aparecieron talleres enfocados en fabricar productos manuales con distintas y variadas materias primas, tales como cuero, estambre, hierro, latón, madera, papel maché, pasta, vidrio soplado y yeso. De acuerdo con Arias (Arias, 2000), la habilidad manual de la gente del municipio influyó en esta temprana diversificación de la artesanía, y al mismo tiempo recreó la capacidad de los tonaltecas para adaptarse a la demanda variada de mercados nacionales, más tarde también internacionales, que exigen y promueven cambios incesantes en el entorno empresarial.

Las evidencias anteriores dejan muy claro que, de una forma u otra, las innovaciones han estado presentes en el ámbito productivo de las artesanías de Tonalá. Y éstas no han perdido de ninguna forma el carácter tradicional que las define como tales. Esto nos lleva a considerar ahora un tipo de distinción necesaria para plantear el manejo de las artesanías, a saber, una categorización de las artesanías que las divide en tradicionales y emergentes. 


\section{LOS DESAFÍOS DEL SECTOR ARTESANAL DE TONALÁ}

El Directorio del Censo Artesanal en Tonalá cuenta con un padrón de 897 empresas registradas. Sin embargo, una gran parte de ellas son pequeños talleres familiares que no cuentan con más de 10 personas trabajando, por lo que la mayoría de estas empresas son microempresas. Estas microempresas familiares están en riesgo de disminuir en gran medida por el hecho de que cada vez son menos las personas interesadas en continuar esta tradición, debido a la baja remuneración económica que perciben. Esta situación se explica, en parte, por la caída de la demanda; actualmente, el municipio de Tonalá exporta de cuatro a cinco contenedores con artesanías por semana, tan sólo el 10\% de lo que exportaban hace 12 años.

Este es un gran problema para el sector económico del Municipio y del Estado, ya que el sector artesanal, además de ser una actividad tradicional que enriquece la identidad local, representa una fuente de empleo e ingresos para la población, y ello justifica la búsqueda de estrategias para la adaptación a los requerimientos del mercado.

Dada la importancia del sector artesanal, según se expuso más atrás, diversas instituciones públicas sean de orden federal, estatal o municipal están interviniendo para fomentar, promover y organizar la actividad artesanal. Para atender a las demandas del sector artesanal, en México existen dependencias como SEDESOL, SEDECO, FONART, entre otras. Estas instituciones ofrecen apoyo al sector artesanal para colocar sus productos, o bien aconsejarlos sobre dónde dirigirse para promoverlos. También se realizan seminarios, foros, encuentros, congresos, ferias por medio de la Comisión de Artesanías, con el objetivo promover la venta de productos artesanales mexicanos.

Las principales causas por las que el sector artesanal se ha mantenido con un perfil bajo y cada vez más disminuido son las siguientes:

A) Falta de una política gubernamental en materia artesanal integral y bien definida

B) Falta de capacidades de adaptación

C) Falta de inversión

D) Ausencia de criterios oportunos de producción

E) Falta de estímulos fiscales

F) No existe un modelo de producción artesanal que permita 
reproducirse por sí mismo y en condiciones diferentes. Recordemos que las condiciones de trabajo y las materias primas difieren en las diferentes regiones del país.

Adicionalmente, las posibilidades de acceso a la educación son bajas para las personas que se dedican a las artesanías, y la falta de innovación en mecanismos de producción, distribución y visión de vida de los artesanos retrasan el crecimiento de este sector manufacturero.

\section{LA EXPLORACIÓN DE VENTAJAS COMPETITIVAS}

Las empresas del sector artesanal tienen potencialidades y factores que las diferencian de otras unidades productivas, y la identificación de ellos puede generar lo que se denomina una ventaja competitiva. A través del descubrimiento y fortalecimiento de la ventaja competitiva, la empresas del sector artesanal podrían alcanzar un rendimiento superior y poder hacer frente a la competencia.

La región y el nicho de mercado en donde se desenvuelven todas las actividades principales de las empresas son sin duda condicionantes para una efectiva creación de la denominada ventaja competitiva. Más aún, el desenvolvimiento mismo de la empresa hacia su interior influye enormemente en las ventajas que la empresa pueda construir y mantener en la posición que ocupa en el mercado. Las empresas que no construyen dentro de su organización la capacidad de anticipar cambios y tomar oportunidades perderán ante competidores que sí lo hacen (Best, 1990).

El éxito o fracaso de una empresa depende, entonces, de disponer de una ventaja competitiva que pueda sostener en el tiempo y en relación a sus rivales potenciales, lo que llevará a la empresa a manejar su competitividad en el entorno en donde se desenvuelve. Esta ventaja puede estar basada en los costos, en el mejor y más racional uso de los recursos que la empresa tiene a su alcance, o en la obtención de un producto diferenciado que satisfaga una demanda específica de los consumidores. Esta estrategia es el eje de la actividad de cualquier empresa y se hace muy necesario en el sector manufacturero que está poblado como ningún otro de pequeñas y medianas empresas. 


\section{LA TEORÍA BASADA EN LA INDUSTRIA.}

De acuerdo con modelo de la organización industrial, una empresa debe dar importancia a los factores del ambiente externo al momento de concebir su estrategia, en relación con su ventaja competitiva, para garantizar su permanencia en el mercado, ya que es ahí donde tiene realmente la batalla comercial. Pareciera que esta teoría impulsa alinear la transformación interior en base a los factores externos, esto es que las parámetros de cambio se encuentran en la dinámica del mercado y es donde se encontrarán las amenazas y oportunidades reales. Este modelo asegura que el éxito de una organización consiste básicamente en ofrecer servicios y productos al más bajo costo que los competidores pero a su vez productos diferenciados que permita hacer que el mercado page precios diferenciados también.

El modelo I/O como también se le conoce, se sirve de los trabajos desarrolladas por el profesor Michael Porter cuya conclusión es que existen cinco fuerzas que haciéndolas trabajar a favor de la empresa determinan la rentabilidad de una empresa siempre y cuando se alinea su estrategia en función de estas fuerzas. Trabajar de acuerdo con la teoría de la organización industrial trae como beneficio que las empresas se preparen ante estas cinco fuerzas que son la Amenaza de entrada de nuevos competidores, La rivalidad entre los competidores, Poder de negociación de los proveedores, Poder de negociación de los clientes, Amenaza de ingreso de productos sustitutos (Porter, 1998), Figura 3. 


\section{Figura 3. Fuerzas de Mercado.}

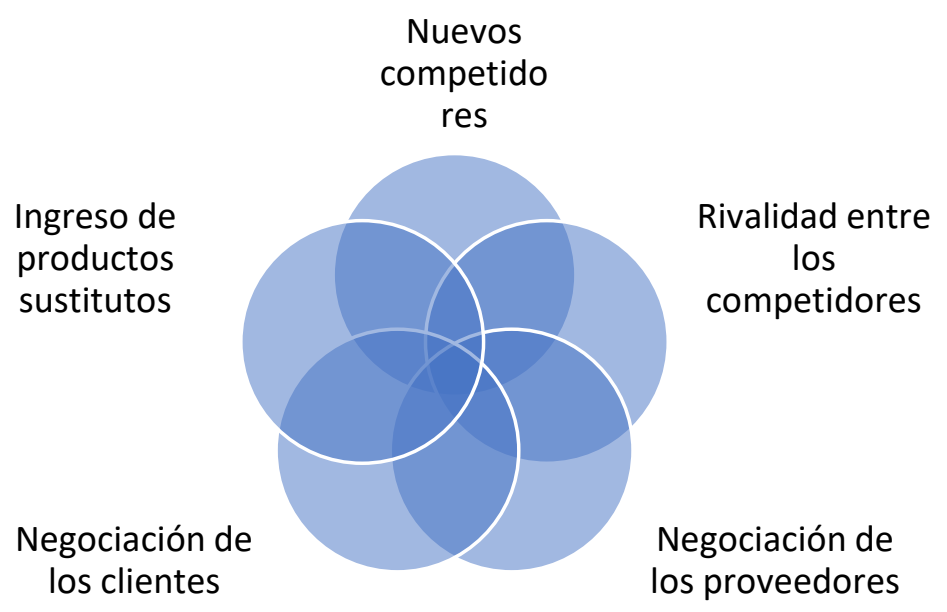

Fuente: Elaboración propia con base a Porter (1998).

La intención de representarlas mediante una intersección de círculos donde cada uno representa una fuerza es plantear que estas fuerzas pueden presentarse de manera conjunta aunque sería casi utópico que al mismo tiempo pero si una combinación de 2 o más, por ejemplo la aparición de un nuevo competidor que introduce además un producto sustituto.

\section{LA TEORÍA BASADA EN LOS RECURSOS.}

El modelo que hace hincapié en los factores internos, para lograr ventajas competitivas en una organización corresponde a la teoría basada en los recursos, y aun cuando pareciera que es inversa al modelo I / O que se enfoca en el ambiente externos, ambas se complementan. La empresa es un conjunto de recursos para producir, estos recursos pueden ser tangibles refiriéndose con ello al equipamiento e infraestructura y recursos intangibles considerándose en ellos el personal. 
Derivado del análisis de estas lecturas se advierte que los recursos pueden ser clasificados de diferentes maneras o bajo diferentes perspectivas, tales como finitos e infinitos, por ejemplo en una empresa serán recursos finitos los recursos materiales y el mismo personal; pero será un recurso infinito la creatividad del personal, el capital intelectual, la imagen corporativa. El crecimiento de la empresa podrá entonces estar limitado según se soporte su liderazgo en el mercado por los recursos y capacidades tangibles y finitos o será su crecimiento ilimitado si soporta en mayor medida su liderazgo en recursos intangibles e infinitos, Cuadro 4.

Cuadro 4. Propuesta de clasificación de recursos.

\begin{tabular}{|c|c|c|c|}
\hline $\begin{array}{l}\text { Recursos de } \\
\text { la empresa }\end{array}$ & Finito & & Infinito \\
\hline Tangibles & $\begin{array}{l}\text { Recursos } \\
\text { financieros, } \\
\text { Instalaciones }\end{array}$ & Materiales, & $\begin{array}{l}\text { Imagen corporativa, } \\
\text { Generación de patentes, } \\
\text { Diversificación de productos }\end{array}$ \\
\hline Intangibles & Personas & & $\begin{array}{l}\text { Creatividad, } \\
\text { Intelectual }\end{array}$ \\
\hline
\end{tabular}

Fuente: Elaboración propia

Los recursos Infinitos e Intangibles se darán como resultados de la expansión como estrategia de crecimiento. La inversión que debe hacerse a la luz de esta teoría va encaminada a la producción, marketing y el talento gerencial, si apreciamos la tabla 7 son inversiones que están orientadas a los recursos finitos que generaran recursos infinitos.

\section{EL PENSAMIENTO ESTRATÉGICO}

Pensar estratégicamente tiene su núcleo en tres grandes preguntas, la calidad de las respuestas a ellas tienen influencia en la asertividad del 
diseño de estrategias, estas preguntas son: ¿Cuál es la situación actual de la compañía?, esta respuesta nace con base a un diagnostico que implique las áreas sustanciales de la empresa y puede ser de forma paramétrica o mediante estudios y análisis del ambiente interno y externo de la organización, la segunda pregunta es ¿A dónde necesita ir la compañía desde su situación? A partir del diagnóstico y alineado a la visión o construyendo la visión si no se tiene, a qué escenario llevaremos a la empresa en un horizonte de tiempo dado. La tercer pregunta corresponde ¿Qué debería de hacer para ir donde necesita y visualiza llegar? Y es aquí donde se desplantan las estrategias y donde se traslada en acciones para que sean ejecutadas por los colaboradores.

"La disciplina del pensamiento estratégico como ejercicio previo y necesario para abordar la planificación, acción y evaluación estratégica no ha recibido el suficiente tiempo". No solo tiempo suficiente sino no ha recibido la importancia que tiene en la formación de los Directores de Negocios, de los Emprendedores y de la capacitación de quienes ya ostentan estos cargos, el análisis estratégico es deseable se elabores con un protocolo que implique estas tres preguntas, Figura 4.

Figura 4. Pensamiento estratégico.

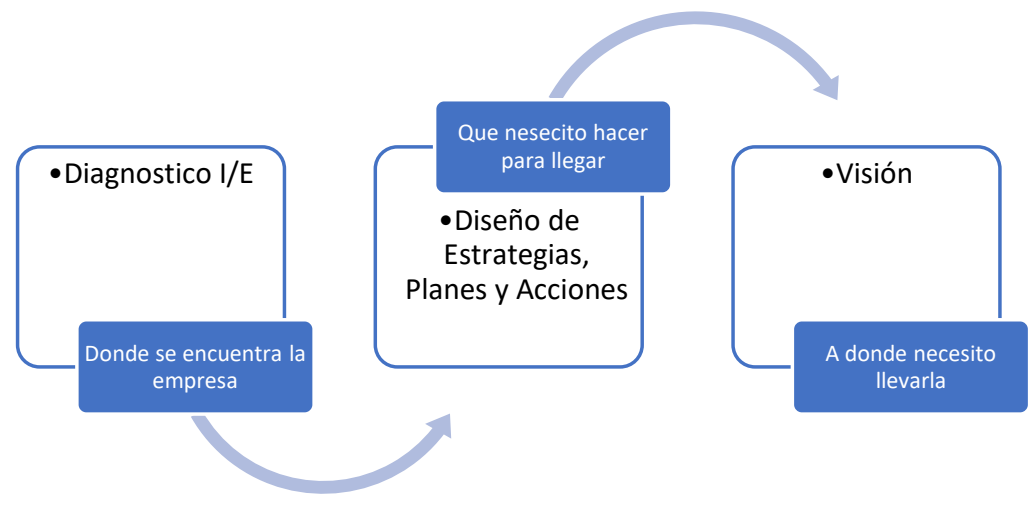

Fuente: Elaboración propia

No se puede determinar que paso o que pregunta es la que se tiene que atender primero, dependerá de los antecedentes que se tengan en la 
organización, así mientras que una empresa tiene identificado su visión, otra empresa podrá estar necesitando precisarla. La secuencia sugerida es Visión, Diagnostico, Estrategia, que son las respuestas a las preguntas del pensamiento estratégico. Una empresa que tiene una estrategia superior es capaz de mantener satisfecho a sus clientes por un periodo de tiempo y de manera continua, para ejecutar esta estrategia es necesario trasladarla a la acción, para crear valor a sus accionistas siendo esto la meta ultima de la estrategia.

\section{LAS PERSPECTIVAS EMPRESARIALES}

Toda empresa vista como sistema tiene a su vez subsistemas se presenten o no de manera tangible, estos subsistemas son las áreas sustanciales de una empresa, dependiendo del tipo de empresa, de su giro son las áreas que se identifican o los subsistemas existentes, sin embargo de manera genérica existen los subsistemas: finanzas, Recursos humanos, Operaciones, Ventas, Dirección. Estas áreas sustanciales o subsistemas son vistas a través de diferentes perspectivas termino que acuña Kaplan y Norton en el concepto de los mapas estratégicos introducido por ellos en el libro en el libro de su autoría Balanced Scorecard - en español Cuadro de mando integral o CMI-. Los recurso y capacidades de la empresa tiene precisamente lugar en las áreas sustanciales de la empresa o en las perspectivas empresariales las cuales son: financiera o de resultado, clientes o mercado, procesos internos y del aprendizaje y crecimiento, Cuadro 5. 
Cuadro 5. Identificación de los recursos y capacidades a través de las perspectivas de la empresa.

\begin{tabular}{ll}
\hline Perspectiva & Recurso y Capacidades \\
\hline Finanzas & Efectivo, Activos, Inversión \\
Del Cliente & $\begin{array}{l}\text { Estudios de Mercado, } \\
\text { Caracterización del clientes, } \\
\text { expectativas }\end{array}$ \\
De Procesos Internos & $\begin{array}{l}\text { Agregación de valor } \\
\text { De Aprendizaje y Crecimiento }\end{array}$ \\
\hline
\end{tabular}

Fuente: Elaboración propia

\section{MODELO DE RELACIÓN PROPUESTO}

Derivado de la revisión teórica se propone un esquema que explique una alternativa para mantener el pensamiento estratégico al momento de diseñar estrategias de competitividad empresarial tomando marco las teorías de la organización y basada en recursos, a través de los temas perspectivas empresariales y las fuerzas de mercado. Esta propuesta se basa en el proceso de administración estratégica, permitiendo encajar las estrategias genéricas de Porter, mediante las cuestiones del pensamientos estratégico, pero además crea un marco para las derivación de estrategias específicas aprovechando los recursos y capacidades de la empresa en función de las fuerza que rigen y más impactan nuestro mercado, contribuyendo a la competitividad y por tanto impactando positivamente la rentabilidad de la empresa, Figura 6 
Figura 6. Diseños de estrategias mediante la relación de los recursos de la empresa y las fuerzas del mercado mediante el pensamiento estratégico alineado a la visión.

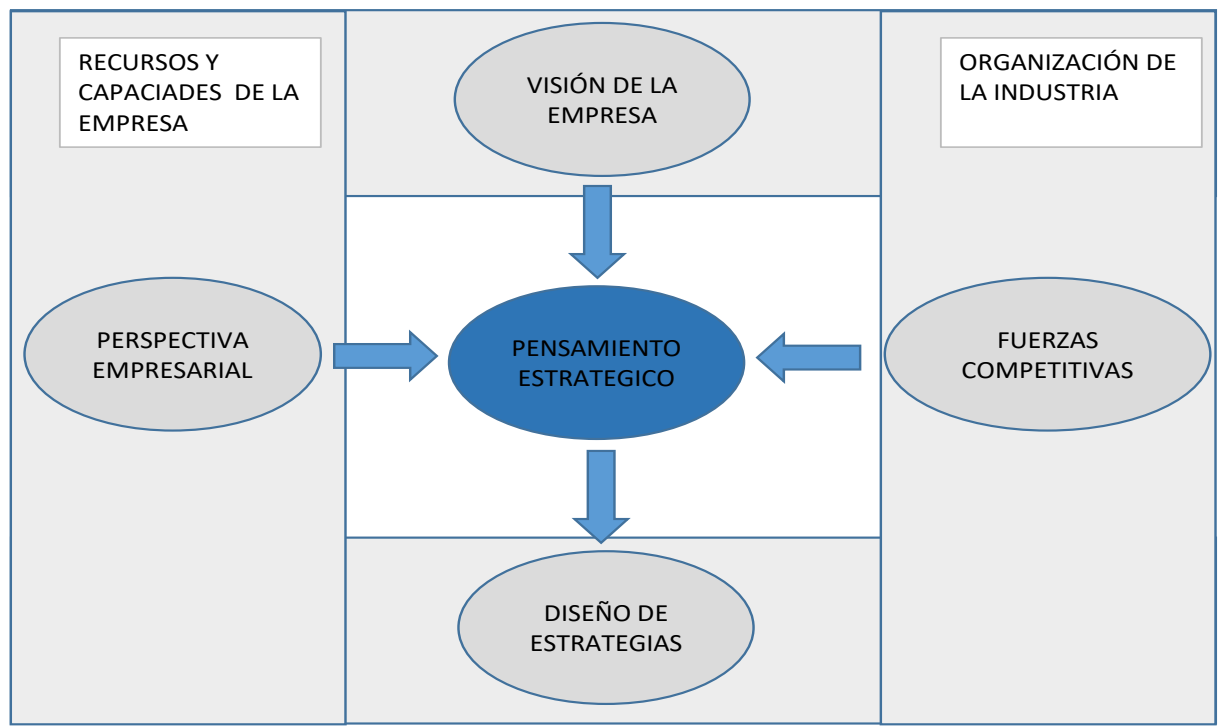

Fuente: Elaboración Propia

En base a esta relación surge un esquema útil para diseñar estrategias que ayuden a la empresas a obtener resultados en términos de rentabilidad y competitividad. 
Figura 7. Modelo de relación de Teorías para la generación de estrategias competitivas.
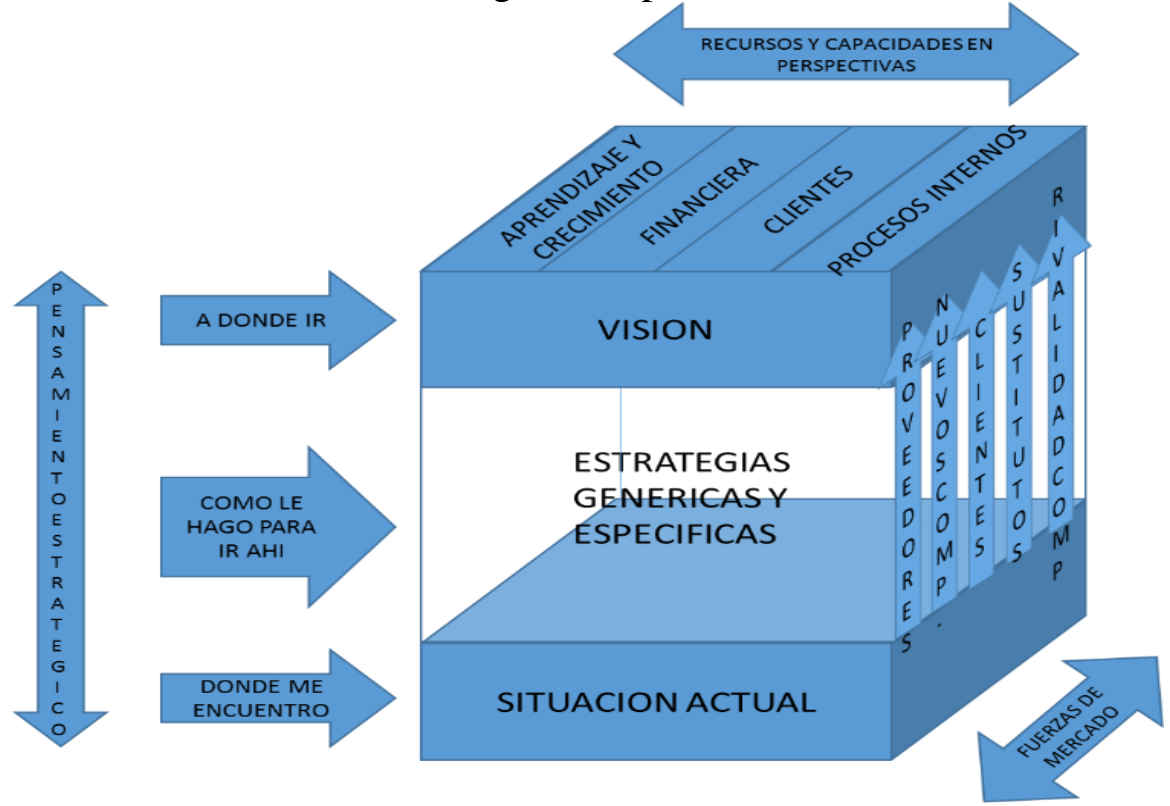

Fuente Elaboración Propia

\section{EL PAPEL DE LA INNOVACIÓN Y SUS POTENCIALIDADES PARA EL SECTOR DE LAS ARTESANÍAS}

La innovación se constituye como uno de los elementos esenciales para lograr que las empresas sean competitivas. La presencia de innovación en procesos productivos como en los productos mismos, es necesaria en cualquier rama del sector manufacturero y la producción de artesanías no es una excepción.

La innovación se define como el establecimiento de una nueva función de producción. El componente principal de la innovación es el conocimiento. El proceso de innovación se considera de naturaleza continua y la organización juega un papel protagónico en el ritmo y el progreso tecnológico.

La economía y la sociedad mejora cuando los factores de producción se combinan de una manera novedosa. El concepto sugiere que 
las invenciones e innovaciones son la clave del crecimiento económico y quienes implementan ese cambio de manera práctica son los emprendedores.

¿Cómo poder innovar? Utilizando la teoría de los recursos y capacidades, y mediante la planificación estratégica, es posible identificar las fortalezas y debilidades de una organización, y con base en ellos explotar las oportunidades y neutralizar las amenazas. Mediante este proceso, los recursos y las capacidades se constituyen en fuente de ventaja competitiva, por lo que ha de apuntarse a la generación de innovación de capacidades distintivas en áreas a lograr ventajas competitivas sostenibles.

La creación de innovaciones como una ventaja competitiva siempre es acompañada y motivada por algún tipo de cambio de la situación presente de la estructura del sector en el que opera la empresa. Ahora bien, este cambio puede tener su origen en los cambios que se producen constantemente en el entorno empresarial. Se entiende por ventaja competitiva "Las características o atributos poseídos por un producto o marca que le confieren una cierta superioridad sobre los competidores inmediatos" (Lambin, 1995). A través de los recursos y capacidades, entonces, la organización puede crear innovación en áreas de producción para ajustar sus estrategias.

La empresa, a través de la estrategia, busca de manera proactiva comprender y anticipar dicho entorno, de manera que pueda adaptarse a los cambios que se produzcan en el mismo, buscando simultáneamente innovar y crear valor para sus clientes y agentes sociales.

La competencia en una industria está enraizada en su economía fundamental y existen fuerzas competitivas que van más allá de los combatientes establecidos en una industria particular. Clientes, proveedores, participantes potenciales y productos sustitutos son todos más o menos prominentes o activos dependiendo de la industria. Una vez que el estratega evalué las fuerzas que afectan la competencia en su industria y sus causas fundamentales, podrá identificar los puntos fuertes de su empresa y sus debilidades, y estará en condiciones de innovar y mejorar. El conocimiento de la capacidad de la empresa y las causas de las fuerzas competitivas destacarán las áreas donde las empresas pueden enfrentar competencia y donde evitarla.

En una rama tradicional como lo es la fabricación de artesanías es muy difícil hablar de innovación, ya que el principal enemigo de la innovación, sin duda, es el temor, el temor al cambio. Además, en el 
ámbito empresarial se tiene la creencia de que sólo las grandes empresas tienen la capacidad para desarrollar innovaciones, y esto deja a las empresas de menor tamaño con temor a emprender innovaciones. Es por ello que, al tratar los desafíos de las pequeñas empresas productoras de artesanías, éstas no deben quedar exentas de la aplicación del concepto de innovación.

El reconocimiento nacional e internacional de las artesanías tonaltecas se ha debido, precisamente, a la capacidad de innovación y adaptación a lo largo de la historia, lo que ha conducido a una gran variedad de artesanías de calidad, además de sus grandes cualidades utilitarias y sus bonitas decoraciones. Por lo tanto, es evidente que los cambios en la forma de producir y entender las artesanías tradicionales, así como la creciente complejidad del panorama productivo, han sido reflejo y respuesta a cambios sociales y económicos (Moctezuma, 2001).

"Sin duda esta tradición, desde la llegada de los españoles hasta la actualidad, continúa experimentando cambios en la forma de producción, en su técnica y, tal vez, también en los elementos decorativos, por la influencia de otras culturas" (Núñez, 2000).

Por lo tanto, la tradición artesanal también puede responder y adecuarse al entorno cambiante de nuestros días, potenciando sus fortalezas, con mayor dominio técnico y de infraestructura, respaldado en las innovaciones de la época. Lo expuesto no significa que las actividades artesanales dejen de lado o pierdan su esencia y la emotividad con la que son concebidas.

\section{LA VISIÓN DE LOS ARTESANOS}

Al ser consultados aquellos artesanos que han introducido innovaciones en sus procesos productivos sobre cuáles han sido los factores que han ayudado a su capacidad para desarrollar sus actividades, las respuestas pueden sintetizarse en los siguientes aspectos: la necesidad de mantener la calidad en la producción de los bienes que se venden, la creatividad del artesano en cuanto al manejo de nuevos diseños en la línea de producción, la falta de venta del producto, obligando con esto a ofrecer nuevos productos, la aceptación de los clientes a través del reconocimiento en el mercado, la adquisición de nueva maquinaria, la capacitación del personal para innovar, la situación económica, adecuándose a las necesidades que 
el entorno reclama, y la necesidad de estar al día con las exigencias del cliente.

En contraparte, se presentan como los obstáculos más comunes que han tenido que enfrentar para el desarrollo de innovaciones: la falta de capacitación, la calidad de los materiales, que dejan mucho que desear e impiden el adecuado desarrollo del producto, la falta de recursos, el alto costo de maquinaria y equipo, la importación de materia prima y la falta de promoción de la artesanía tonalteca.

\section{CONCLUSIONES}

De acuerdo con el desarrollo del tema y en concordancia con los planteamientos de este trabajo y el análisis de información, concluimos que el pensamiento estratégico es un factor que al tenerlo presente durante el análisis de las fuerzas competitivas y la evaluación de los recursos y capacidades de la empresa a través de las perspectivas o áreas sustanciales de la empresa permite o contribuye para que la selección de estrategias genéricas sea de manera adecuada o bien para que el diseño de estrategias específicas sean de mayor impacto y lleven a la empresa desde la situación actual a la situación deseada que a su vez está alineada con la visión de la empresa, buscando desarrollar o crear ventajas para la empresa. Estos principios son válidos también para el fortalecimiento del sector artesanal.

La competitividad es una característica que se ha hecho patente por el fenómeno de la globalización La globalización por sí misma no es mala ni buena sino es la gestión la que marca el impacto de la misma (Stiglitz, 2002). En este sentido, el trabajo en la gestión puede ser el inicio, la plataforma para desarrollar el desarrollo de una herramienta empresarial que fortalezca al sector artesanal, asumiendo un papel activo, provocado las operaciones comerciales y no realizarlas por el empuje o arrastre de otras empresas sino por el buen uso de nuestros recursos y capacidades para control de las fuerzas competitivas.

Con base al modelo de relación planteado en este trabajo se puede diseñar una metodología aplicable al sector artesanal que considere lo siguiente: 
- Diagnostico paramétrico y administrativo para determinar la situación de la empresa analizándola a través de la teoría de los recursos y capacidades de la empresa.

- Diseño de estrategias específicas o selección de las genéricas en función de los recursos con que se cuenta y los que potencialmente genera la empresa para controlar las fuerzas del mercado con base a la teoría de la organización de la industria.

- Plan de acción que se centre en los recursos finitos de la empresa para generar los recursos infinitos que logran competitividad.

- Tablero de control que permita determinar la efectividad de las estrategias y acciones.

- Alineación a la visión de la empresa.

A manera de sello de esta conclusión y como fruto del análisis realizado, consideramos que el pensamiento estratégico es un factor que puede influir en la competitividad del sector artesanal por la generación de estrategias que son fácilmente trasladadas a la acción.

El éxito de una organización depende en gran medida del aprovechamiento de los conocimientos y habilidades, de la gran creatividad innovadora y de la motivación tanto de su personal como de sus aliados como: proveedores, colaboradores o los propios ciudadanos, clientes y usuarios de los productos así como del aprendizaje organizativo, todos ellos circunscritos en la cadena de valor de la organización.

Todo esto surge al considerar a las empresas como entidades de aprendizaje, las organizaciones que gestionan la información y generan conocimientos que se plasman en productos y procesos productivos nuevos o mejorados, en otras palabras, en innovaciones. Ante tal situación, una organización para mantenerse en competencia, y así poder liderar el segmento de mercado donde se encuentra inmersa y luego expandirlo a nuevos mercados, debe experimentar un proceso de mejoramiento continuo, apalancándose en el aprendizaje y la innovación.

En el caso de los artesanos, el problema es que muchos no quieran correr riesgos con inversiones para la obtención de nuevas tecnologías y el desarrollo de nuevos productos para el mercado, porque tienen el temor al cambio, temor a fracasar como consecuencia de estos cambios, y prefieren seguir trabajando con sus rutinas, tal como hicieron sus padres.

Por otra parte, en el caso de los que deciden dar el paso, las 
innovaciones suelen estar enfocadas principalmente en los productos, más que en los procesos productivos. Dichas innovaciones resultan ser incrementales, es decir, consisten en la adecuación y mejora continua de los productos ya existentes. Aquellos que realizan innovaciones radicales en los productos lo hacen, básicamente, mediante diseños exclusivos que se realizan en base a peticiones hechas por los clientes o personajes de moda de caricaturas o películas.

Es más evidente, entonces, que la mejora y el perfeccionamiento continuo en la línea de productos, además de ofrecer diseños a la medida de los clientes y enfrentarse a nuevos mercados, se constituyen en condiciones de las que se sirven las empresas artesanales analizadas para mantener su competitividad en el mercado. Es decir, la innovación se presenta como factor estratégico de competitividad en este tipo de empresas.

Los artesanos están conscientes de que el mantener la tradición en la producción de sus bienes es una necesidad que deben cumplir para preservar a las artesanías como un legado que les han dejado sus antepasados y que durante tanto tiempo ha colocado a Tonalá en un lugar privilegiado, tanto a nivel nacional como internacional.

Sin embargo, también hay una necesidad enorme de estar a la vanguardia en los procesos internos y los requerimientos del mercado, debido a los cambios que presenta el mundo con la globalización y mayor competencia. Por lo que el aspecto de la innovación inevitablemente se constituye como un factor estratégico que les ayudará a adecuar sus procesos productivos y a modificar sus líneas de producción conforme a la demanda del mercado, orillando con esto al mantenimiento de su competitividad en el entorno en el que se desenvuelven.

\section{BIBLIOGRAFiA}

Aragón C. (2003). Maestros en empresa familiar. Publicaciones de la universidad de Deusto.

Arias, P. (2000), De villa alfarera a ciudad dividida. En Miranda Beatriz Núñez (coord.), Tonalá, una aproximación a su estudio. El Colegio de Jalisco, México.

Best, M. (1990). Theoretical Perspectives on the Firm. The New Competition: Institutions of industrial restructuring. Harvard 
University Press, Cambridge, Massachusetts.

Cabrales, L. F. (2000), Proceso de metropolización y segregación social tonalteca. En Miranda Beatriz Núñez (coord.), Tonalá, una aproximación a su estudio. El Colegio de Jalisco, México. p. 65-90.

Carrión J. Ortiz M. (2000). La Teoría de Recursos y Capacidades y la Gestión del Conocimiento. Recuperado de http://www.gestiondelconocimiento.com/documentos2/juan_ carrion_maroto/articulo_acad_recursosycapc.htm.

INEGI. (2010). México, Censos 2010.

Lambin, J. J. (1995): Marketing estratégico, Mcgraw-Hill. 3ra edición.p.19-34.

López C. Cota R. (2007) la presencia de innovación como factor estratégico de competitividad en el caso de las empresas que producen artesanías.

Mateos, G. (2007). Tonalá de ayer. San Juan de Dios mercado alfarero. Amateditorial. México.

Moctezuma Y. P. (2002), Artesanos y artesanías frente a la globalización: Zipiajo, Patamban y Tonalá. El Colegio de San Luis y El Colegio de Michoacán, FONCA, México.

Moctezuma Y. P. (2001), La subversión de lo indígena en las fronteras de la tradición popular. En Tonalá: Artesanía y tradición, Estudios Jaliscienses, No. 44:18-39.

Mintzberg, H. Quinn, J.(1995). Análisis de estrategia. EL PROCESO ESTRATEGICO. Prentice Hall Inc.2da edición.

Núñez, B. (2000), Permanencia y heterogeneidad cultural, El Colegio de Jalisco, México.

Núñez, B. (2000), Tonalá, una aproximación a su estudio. El Colegio de Jalisco, México. P.129-152.

Porter, M. (1998). On competition. Cambridge, MA: Harvard Business School Press.

Schumpeter, J. A. (1996), Capitalismo, Socialismo y Democracia. Ediciones Folio, Biblioteca de Economía. España, 1996.

Schumpeter, J. A. (1978), Teoría del desenvolvimiento económico. FCE. México.

Ward, J. (1994) investigando sobre el crecimiento de la empresa familiar. 